\title{
Reconstructive Endoscopic Myomectomy
}

\author{
Atef M.M. Darwish \\ Department of Obstetrics and Gynecology, \\ Woman's Health University Hospital, \\ Assiut \\ Egypt
}

\section{Introduction}

Myomectomy is an old reconstructive gynecologic operation intended to preserve a functioning uterus suitable for a possible subsequent pregnancy. A lot of the published work on endoscopic myomectomy demonstrates the feasibility of the procedure, highlights the possible advantages, and expresses the skills of the surgeons (1). The question now is not whether the procedure is feasible endoscopically, but whether the endoscopic approach is superior and beneficial to a particular patient as well as cost effective for the community at large (2). Modern practice should be focused on evidence-based medicine (EBM) concept (3).

\section{Principles of reconstructive surgery}

Reconstructive surgery aims to put genital organs and tissues back together in a way that makes them more functional, and /or with fewer clinical symptoms. It leads to reduce potential problems and side effects from primary surgery and improve patients' quality of life. Early discharge within 24 hours after the procedure with an excellent outcome is a common sequel to reconstructive gynaecologic surgery even if done via laparotomy (2). Nevertheless, reconstructive surgery requires high level of expertise, delicate instruments, fine maneuvers, longer time, and fine energy modalities.

\section{Fertility-preserving reconstructive gynecologic surgery}

If future fertility is of concern, endoscopic reconstructive gnecologic surgery should follow microsurgical principles $(4,5)$ which include avoidance of serosal insults e.g. tissue trauma, ischemia, hemorrhage, infection, foreign-body reaction, and leaving raw surfaces (6). Other microsurgical principles include minimizing tissue trauma by using atraumatic techniques, meticulous hemostasis, complete excision of abnormal tissues and precise alignment and approximation of tissue planes (7). With this so meticulous reconstruction of the gynecological structures, maximal possibilities of pregnancy without the utilization of other complex procedures of assisted reproduction can be achieved. It has been estimated by some enthusiastic proponents that microsurgery could results in double the pregnancy rate compared conventional macrosurgery (8). However, a recent Cochrane review did not demonstrate any advantage of microsurgery over the conventional approach (6). 
Laparoscopic microsurgeons should have enough experience in classical microsurgery as well as highly-developed two-handed laparoscopic skills for intracorporeal knotting $(9,10)$.

\section{Reconstructive laparoscopic myomectomy (LM)}

The first LM is performed in 1980 when several pedunculated subserous fibroids are removed laparoscopically (11). Since then, several descriptive series $(12,13)$ on LM have been published and these have highlighted several problems associated with the procedure. Long operating times have been reported with some exceeding seven hours (14). This may be related to the need to morcellate the fibroids to facilitate their removal as well as the need for laparoscopic suturing which can be tedious (15). Increased adhesion formation has also been described following this procedure (16). Furthermore, several authors (17-19) have also reported cases of uterine rupture/dehiscence following LM. More attention should be paid to careful uterine repair following this laparoscopic procedure. A large series of pregnancies after LM (20) reported on 100 patients who eventually had deliveries, and recorded only one uterine rupture occurred at the site of the old LM scar $(1 \%$; $95 \%$ CI, $0.0-5.5 \%)$. Although the authors concluded that spontaneous uterine rupture seems to be rare after LM, they caution and re-iterate that particular care must still be given to uterine closure. Data on the risk of recurrence after LM has been published (21) in a series of 622 patients monitored with ultrasonography. They reported a cumulative 10 year recurrence rate of $27 \%$. Although several authors $(13,22)$ have reported pregnancies after LM, there are still no long term data on subsequent fertility following the procedure. Mais et al (23) conducted a prospective RCT comparing early postoperative outcome following LM and laparotomy in 40 patients. They reported less postoperative pain, a shorter hospital stay and a faster rate of recovery after laparoscopy as compared to open surgery. Several authors $(11-14,21)$ have suggested that laparotomy may be preferable to the laparoscopic approach in patients with large multiple myomas, especially in the presence of severe endometriosis. In general, LM is associated with a shorter hospital stay, faster recovery and less blood loss that could be explained in part by the tamponade effect of the pnuemoperitoneum. Patient satisfaction with operative scar after LM is good (24) and as well as fertility satisfaction and reproductive outcome (23).

\subsection{Patient selection}

Indications include infertility, recent and significant uterine enlargement and symptoms like pelvic pain, pressure, menometrorrhagia and abnormal bleeding (25). Inclusion criteria include age $\leq 42$ years, the presence of at least one symptomatic myoma $>3 \mathrm{~cm}$, and a number of myomas equal or less than seven $(26)$. Some authors $(27,28)$ suggested that no more than three or four myomas with diameters $<7-8 \mathrm{~cm}$ are to be removed; Nevertheless, the decision should be individualized according to the surgical skills, facilities, age and the pathologic findings $(29,30)$.

\subsection{Role of LM in infertility}

Whether to perform LM or open microsurgical minilaprotomic myomectomy is a controversial issue. Added to the well documented advantages of laparoscopy, LM is associated with fewer postoperative complications and since no preoperative or intraoperative factors seem to influence the fertility outcome in women with uterine myomas, it is considered as the treatment of choice in infertile patients (31). Those infertile 
cases with myomata are mostly hyperestrogenic; so laparoscopy will help treat associated lesions particularly endometriosis.

\subsection{Preoperative preparation}

You should get a consent for either LM or emergency laparotomy whenever required if technical problems or excessive bleeding would be encountered. The size, number, and location of the fibroids as well as the experience of the surgeon all must be factors in the decision to proceed with the laparoscopic approach. Although several suggestions have been made, opinions differ. Whether to use preoperative hormonal preparation or not is still a controversial issue. Some studies reported on significant reduction of the myoma size and introperative blood loss on gonadotrophin-releasing hormone agonist or antagonist. Zullo et al (32) noted that preoperative use of leuprolide acetate decreased estimated blood loss from $172 \mathrm{~mL}$ to $132 \mathrm{~mL}$ and operating time from 113 minutes to 99 minutes. Felberbaum et al (33) reported on significant preoperative reduction of uterine fibroids in only 16 days by administration of a gonadotrophin-releasing hormone antagonist (Cetrotide). On the other hand, longer operative times, 112 minutes versus 157 minutes, with preoperative GnRH analog use found by Campo and Garcia, are attributed to difficulty in detecting the myoma cleavage plane (34). My practice for a long time is to give patients medorxyprogesterone acetate $15 \mathrm{mg}$ daily for 20 days prior to LM and I notice good surgical field in most of cases.

\subsection{Operative technique}

LM is usually performed with a standard technique using three suprapubic ports. The uterus is always cannulated to allow the correct exposure of myomas. For pedunculated myomas, the pedicle are secured using a pre-tied or extracorporeally-tied loop and coagulated and transected with bipolar forceps and scissors. For subserous and intramural myomas, serosal incision should be made vertically over the convex surface of the myoma using a monopolar hook, fine needle or one blade of a scissors (Figure 1).



Fig. 1. Uterine incision.

After exposure of the myoma pseudocapsule, grasping forceps is positioned to apply traction to the myoma and expose the cleavage plane (figure 2). An option is to use a $10 \mathrm{~mm}$ myoma driller from a midline incision to hold and grasp the myoma firmly against the anterior abdominal wall to facilitate enucleation. Enucleation is carried out by traction on the fibroid and by division with a unipolar hook or needle or mechanical cleavage. 


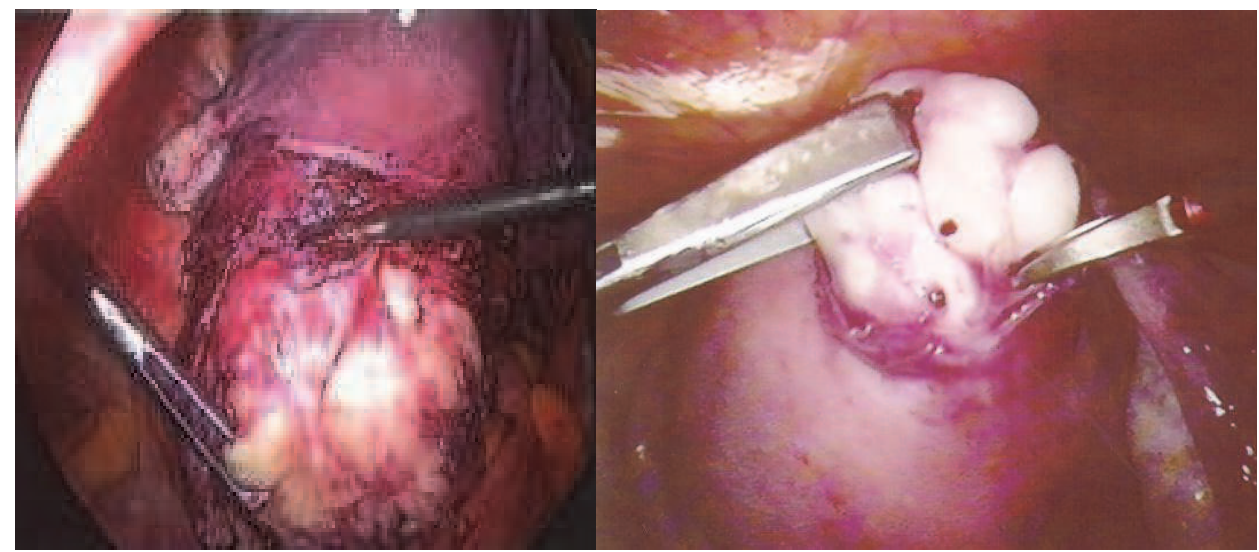

Fig. 2. Myoma enucleation.

Hemostasis during dissection is achieved by bipolar or spray monopolar coagulation. Suturing is usually done along one or two layers including the serosa depending on the depth of incision with interrupted, simple or more frequently cross-stitches tied intracorporeally using 1 or 0 Polyglactin sutures or any delayed absorbable sutures (figure 3 ).

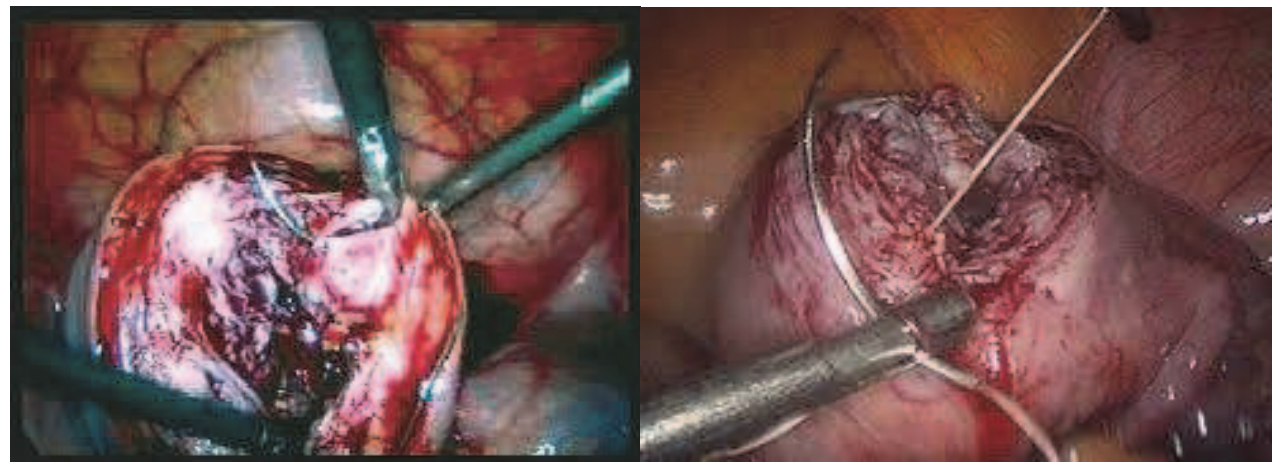

Fig. 3. Closure of the uterine defect with sutures.

A recent study (35) evaluated the use of bidirectional barbed suture and found it significantly shortens the mean duration of surgery.

Morcellation of the myoma is followed by irrigation and placement of adhesion barrier. As a trial to reduce bleeding during LM, Zhao et al (36) tested loop ligation of larger myoma pseudocapsule combined with vasopressin before LM and found it very effective in minimizing bleeding in a randomized controlled trial.

Removal of the fibroids can be performed using morcellation (figure 4), minilaparotomy, or colpotomy Alternatives to these are to destroy the fibroids in place with cryotherapy, bipolar cautery, or laser. No trials have compared these techniques to determine which is the safest or most effective. Chen et al (37) tried simultaneous enucleation and in situ morcellation of myoma and found it convenient. Don't forget to leave an intraperitoneal drain for few hours via an auxillary portal. 

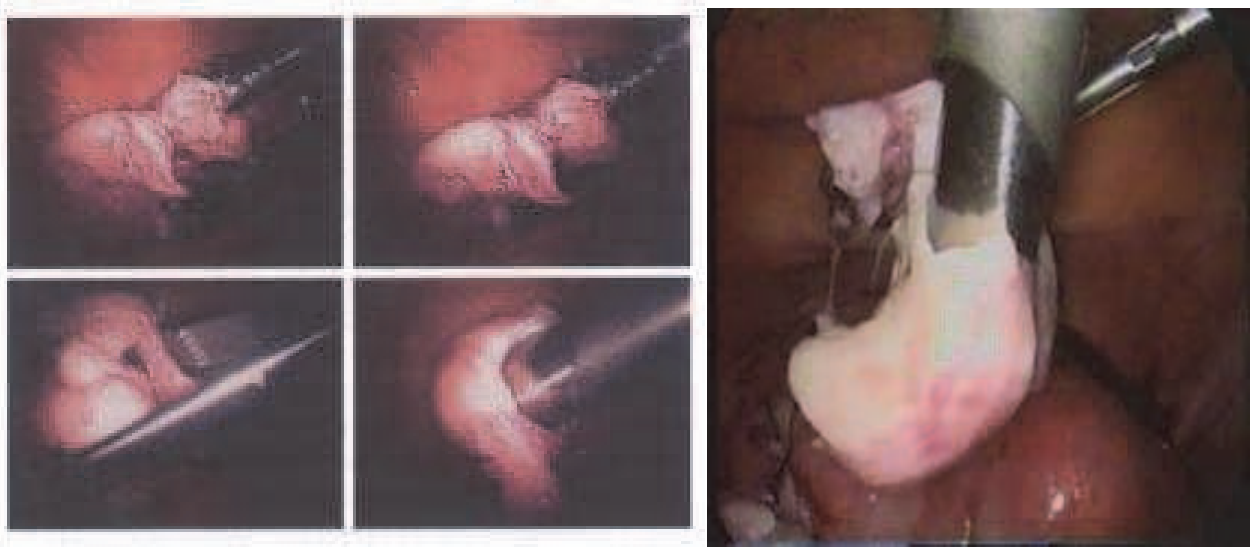

Fig. 4. Morcellation of the myoma.

\subsection{Disadvantages of LM}

Although LM has been shown to be feasible, the technique is fraught with problems. Furthermore, its place in the treatment of infertile patients still needs to be defined. Laproscopic closure of the uterine incision is performed in a rather simplified manner utilizing just few stitches, unlike conventional open myomectomy. There is a need for meticulously studying the healing pattern of the uterine incision following LM. Integrity of uterine scar is an important consideration for women desiring pregnancy. LM is accused to be a procedure that leaves behind insecure uterine scars as evidenced by reported cases of uterine rupture following LM. Although uterine ruptures during pregnancy have been reported after myomectomies via laparotomy, these are usually sporadic reports $(14,15,17,38-40)$. Risk factors for uterine rupture after LM may be intramural haematoma formation at the incision site, tissue necrosis because of thermal damage leading to defective scar formation, or incorrect approximation of incision edges leading to healing by secondary intention. Uterine rupture and fistula formation after LM have been reported $(14,15,17,40-42)$. However, none of these investigators closed the uterine defect in layers. In another series (43), no case of uterine rupture has been reported following pregnancies after LM. The authors have emphasized the importance of avoiding excessive thermal damage and of adequate uterine repair using multiple layer suturing techniques. In cases of deeply embedded myomas, larger than six to seven centimetres in size, LM may be replaced with laparoscopic assisted myomectomy (44). Suturing the myometrium in layers during a LM is also necessary to prevent iatrogenic adenomyosis (45).

\subsection{Postoperative care}

Like any laparoscopic surgery, LM cases should be monitored. Care of the amount of blood loss in the drainage set. Better to prescribe antibiotics and antipyretics whenever required. Instruct you patient to avoid vagina manipulations or douches if posterior colpotomy is performed. Moreover, she has to avoid sexual intercourse for at least 4 weeks if colostomy is performed. I don't recommend advising pills for contraception as those cases are usually infertile. She has to use a local method for 1-2 months only. 


\subsection{Follow-up}

Our school since 1992 is to follow up cases by both transabdominal and transvaginal ultrasonography to properly evaluate healing of the scar till complete disappearance of the signs of healing.

\subsection{Assessment of the integrity of the uterine scar following LM}

Various modalities to assess scar healing and strength in the postoperative period have been suggested (46). Ultrasonography is used to detect haematoma formation in the uterine scar. Doppler studies can be used to assess the uterine scar, possibly recognizing the irregularities in the vascular patterns and haematoma formation, which depict poor quality uterine scar. Velocimetric findings at $30^{\text {th }}$ postoperative day may be able to assess the healing process. A high resistance index may suggest abnormal healing and an area of fibrosis $(47,48)$. Hysterosalpingography, despite being non-specific, may be performed to detect the presence of any fistulae (15). Second-look laparoscopy may be carried out between four to eight weeks postoperatively and a methylene blue test is performed to check any uterine fistula. The place of second look laparoscopy has been particularly emphasized in relation to assessment of any postoperative adhesions and its treatment $(48,49)$.

\subsection{Impact on reproductive health}

Again, those cases are usually hyperestrogenic with evidence of adenomyosis uteri, endometrial htperplasia or endometriosis. So, laparoscopy allows proper assessment of those infertile cases. If an office hysteroscopy is performed prior to LM, this would be considered as one of the keys of success regarding future fertility. Therefore, LM would help solve the infertility problem of those cases. Adding the advantages of laparoscopic surgery with definite lower risk of adhesion formation if compared to laparotomy would favor LM.

\subsection{LM versus conventional myomectomy}

There is no difference in fertility efficacy outcome if fibroids are removed via laparotomy when compared to laparoscopy (50). Because hematoma formation of measurable size is not normal in wound healing, subsequent uterine rupture may be related to poor wound healing in the presence of hematoma (51). We studied 22 cases that are treated with LM followed by suturing of the incision in two or three layers trying to mimic open myomectomy (52). Moreover, we studied 169 cases treated with conventional open myomectomy with meticulous closure of the incision in multilayers (53). Laparotomy study (53) included many cases with multiple myomata (mean number is $2 \pm 0.4$ ) and of varying size (mean size is $216 \mathrm{~cm} 3 \pm 61 \mathrm{~cm} 3$ ). Paradoxically, despite having myomata of smaller size with less mean numbers, the laparoscopy study (52) demonstrated higher percentage of hematoma formation in the early postoperative period ( $74 \%$ versus $24 \%$ for laparoscopy and laparotomy studies respectively). This highlights the superiority of open microsurgery in terms of meticulous suturing simply because it is technically more feasible than laparoscopic suturing. Continuous training of endoscopists on improving suturing techniques and innovation of easier suturing devices would facilitate thorough laparoscopic multilayer suturing of the myomectomy scar. Nevertheless, the impact of the early postoperative hematoma on wound healing is not clear so far. At 4-6 weeks postoperatively, the incidence of hematoma formation in both studies $(52,53)$ declined markedly $(8 \%$ at 6 weeks versus $7 \%$ at 4 weeks for laparoscopy and laparotomy studies respectively). Thus, the procedure 
should involve multilayered uterine closure to avoid hematoma formation, weaker scar and subsequent rupture. However, the only way to answer the question as to whether LM can ensure a safe obstetric outcome as open myomectomy, is to perform a large multicenteric comparative trial. LM offers significantly less febrile morbidity, lower transfusion rates, and shorter hospitalization stays if compared to open myomectomy (54). Moreover, it results in shorter operative times and lower postoperative hemoglobin, while hospital stay and pain are less in the laparoscopic group if compared to laparotomic approach (55).

\section{Reconstructive hysteroscopic myomectomy (HM)}

Submucous myoma may cause abnormal vaginal bleeding, pain, \&/or infertility. The incidence of myoma in women with otherwise unexplained infertility is estimated to be 1.0$2.4 \%(56,57)$. A systematic review of 11 cohort studies suggests that women with submucous myoma have lower pregnancy rates compared with women with other causes for their infertility (RR 0.30, 95\% CI 0.13 to 0.70 ). HM is not associated with an increase in live birth rate (RR $0.98,95 \%$ CI 0.45 to 2.41 ) but is associated with a higher pregnancy rate (RR 1.72, 95\% CI 1.13 to 2.58) (58). Both HM and polypectomy appeared to enhance fertility compared with infertile women with normal cavities in one study (59). HM currently represents the standard minimally invasive surgical procedure for treating submucous fibroids, with abnormal uterine bleeding and reproductive issues being the most common indications $(60,61)$. Nevertheless, this technique is associated with significant risks of excessive bleeding, prolonged operative time required for cutting the myoma into chips of tissues and extractiing them, risks of fluid overload, and the possibility of incomplete resection and perforation (62). To reduce these risks, more effective patient selection and improved techniques are necessary (63).

\subsection{Indications of HM}

It is well established and settled that all evidence consider HM as the gold standard and nearly the only line of therapy of submucous myomata of suitable size. The problem is the definition of "suitable size". Most centers consider 2-4 cm as an optimal size. If larger myoma is diagnosed, HM can be tried either on 2 session bases or utilizing our modified technique (see below). An important issue is the association of adenomyosis or intramural myomata. You can excise more than one myoma on the same setting provided the general condition of the patient can tolerate.

\subsection{Preoperative preparation of HM}

Patient selection is essential to achieve resolution of bleeding symptoms, enhance fertility, and reduce surgical risks. Preoperative imaging with MRI, 3-dimensional ultrasonography or saline-infused sonohysterography (SIS) can provide a map of the uterine myomas and identify the intramural component of the fibroids. The European Society of Hysteroscopy designed a classification system for submucosal fibroids based primarily on this concept (64, figure 5).

- $\quad$ Type 0 fibroids are pedunculated with no intramural component.

- Type I fibroids are sessile submucosal fibroids with less than 50\% intramural component.

- $\quad$ Type II fibroids have a greater than $50 \%$ myometrial invasion. 


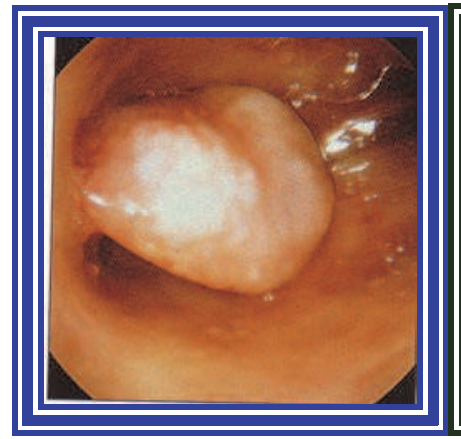

Type 0

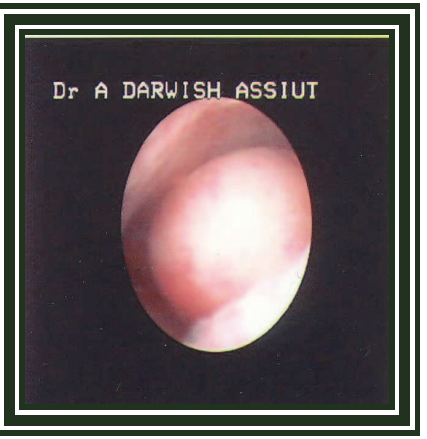

Type 1

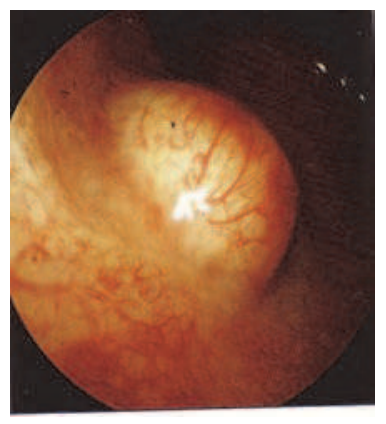

Type 2

Fig. 5. Classification of submucous myomata.

Incomplete resection of the fibroid is more likely in type II fibroids with more extensive intramural component. Calculated from one study is a $50 \%$ chance per procedure of complete resection of type II fibroids, $60 \%$ of type I fibroids, and $92 \%$ of type 0 . After an incomplete resection, the residual intramural component is likely to be expelled into the cavity and a second procedure is often successful. The patient with type II fibroids should be counseled on the risk of failure and the procedure should be performed by experienced hysteroscopic surgeons (65).

Preoperative hormonal preparation of the myoma is a controversial issue. HM should be performed essentially postmenstrual. Preoperative cervical ripening with a prostaglandin analogue has been demonstrated to facilitate cervical dilation. In a controlled randomized study (66), we succeeded to prove that Misoprostol $200 \mathrm{mcg}$ applied vaginally 8-12 hours prior to surgery is well tolerated and can decrease surgical time and reduce the risk of surgical complications.

\subsection{Techniques of $\mathrm{HM}$}

Myoma resection is usually performed with a loop electrode (figure 6) by shaving the visible portion of the myoma into small pieces. Sometimes, myomas deeply embedded in the myometrium cannot be completely excised. Other techniques for removing the myoma hysteroscopically include using an Nd:YAG laser fiberor electric myoma vaporizer (65).

Various sizes of operating hysteroscopes are now available, but they all include a telescope with a fiberoptic light source and camera. The angle of the telescope is either $0^{\circ}$ or an acute angle of $12-30^{\circ}$. The straight visual $0^{\circ}$ scope might be helpful with fundal myomas but an angled perspective is more commonly used for fibroid resection. The telescope inserts through an external sheath and internal sheath for continuous outflow and inflow of distension media. The working element of the operating hysteroscope is the resecting loop that is available in many sizes and angles. The electrosurgical energy connected to the loop can be monopolar or bipolar. With the monopolar loops, using nonionic distension media such as glycene $5 \%$ or sorbitol $1.5 \%$ is necessary. With bipolar loops, both electrodes are within the cavity and normal saline can be used for distending solution. For hysteroscopic myomectomy, various laser types and mechanical loops without electrical energy have also been described (65). 


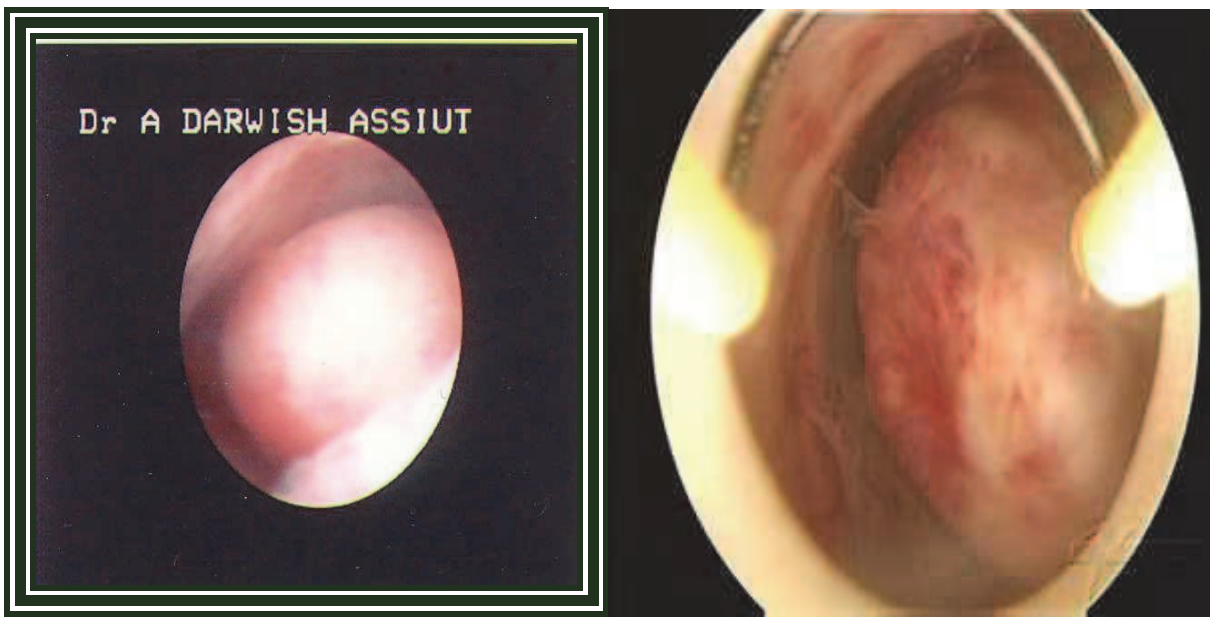

Fig. 6. Myoma cutting with the resectoscope.

There are multiple methods of using the electrosurgical loop to optimize fibroid resection (figure 7). To maintain good visualization, fragments of resected fibroid need to be removed during the procedure. The surgeon may transfer fragments out of the field of resection or retrieve them from the cavity by grasping the tissue with the resecting loop. An intrauterine morcellator has recently been introduced that may improve surgical time by aspirating fibroid fragments through the hysteroscope (65). When applying the monopolar loop, currents as high as 75-150 W are required for smooth tissue cutting. Current should only be applied while the loop is being retracted into the hysteroscope or while the entire resectoscope is being pulled away from the fundus. A combination of the 2 movements is used by the surgeon to safely and effectively slice through the tissue.

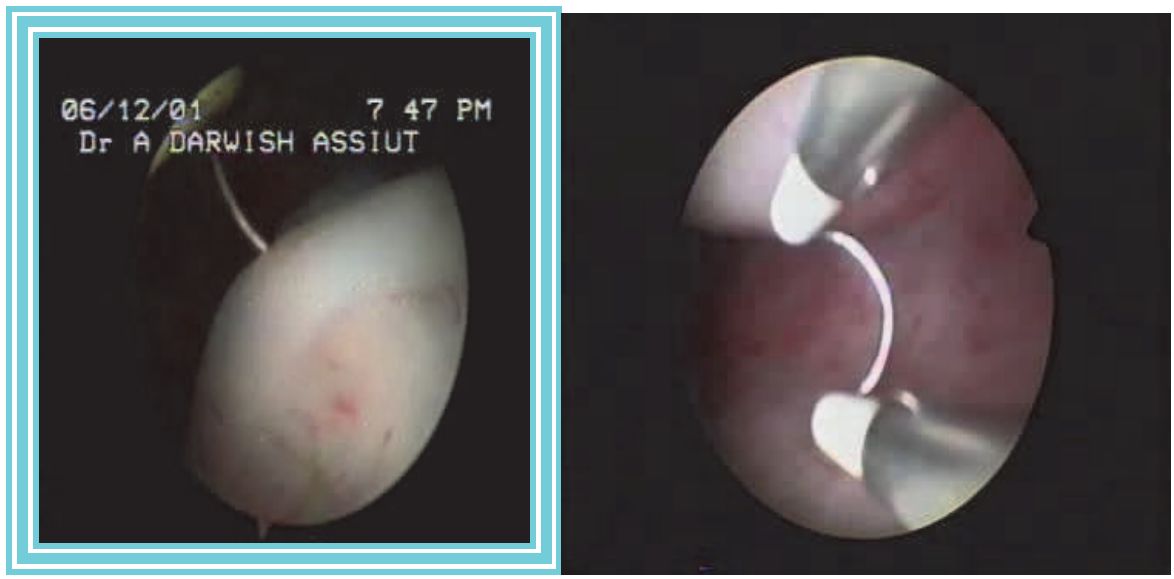

Fig. 6. Resectoscopic myomectomy.

Resection of type 0 fibroids can be accomplished in 1 step by most hysteroscopic surgeons since the border of the fibroid with the endometrium is easily identified (67). Type I and 
type II fibroids require more surgical expertise as resection of the fibroid extends into the myometrial space. Intraoperative cervical injection of carboprost, a methyl analogue of prostaglandin F2-alpha, has been shown to cause uterine contractions and thereby squeeze the remaining fibroid into the cavity to facilitate a single step. Concomitantly performing laparoscopy with intramuscular injection of prostaglandin F2-alpha is also effective for resection of large fundal fibroids and provides transabdominal visualization (68). In many circumstances, resection of large fibroids with significant intramural component is a 2-step approach since there is often further intracavitary expulsion of the fibroid after the initial surgery. The second procedure can be performed 3-6 weeks later when the residual fibroid has migrated into the submucosal space (69).

\subsection{Modified HM for big or intramural myomas: Darwish's technique (70)}

All cases should be subjected to office hysteroscopy in the immediate postmenstrual period not preceded by hormonal priming. The objectives are to confirm the sonographic diagnosis of myoma, comment on the number and the size, assess the site of the myoma in relation to the tubal ostia and the uterine walls, detect any pedicle and to estimate the depth of the myoma in relation to the uterine wall. If more than half of the myoma protrudes into the endometrial cavity, the case will be considered a submucous myoma. If the intramural part is more than the intracavitary part, the case will be considered an intramural myoma (type II).

Modified resectoscopic technique starts 8 hours prior to the time of surgery by inserting 200 $\mu \mathrm{g}$ misoprostol intravaginally to allow softening of the cervical canal and the myoma itself. The resectoscope is used to make a deep circumferential incision all around the base of the myoma (figure 7) until complete separation occurs and the myoma became completely free inside the endometrial cavity.

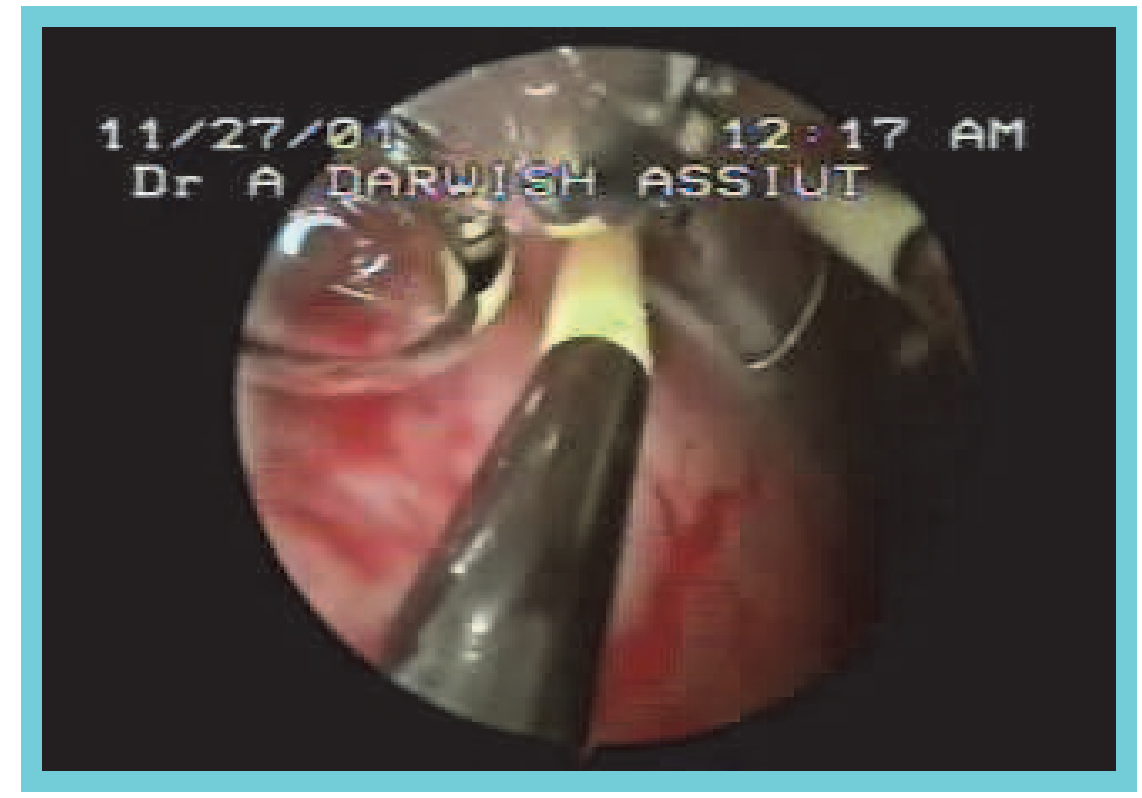

Fig. 7. Circumferential incicion. 
This crucial step required changing the angle of the loop electrode into 15 degrees below the horizontal plane to allow easy access to the base. Cutting is made $3-4 \mathrm{~mm}$ from the base towards the myoma side to preserve some healthy endometrium for postoperative creeping to cover the row area of the myoma. A specially designed $2 \mathrm{~mm}$ myoma driller simulating the laparoscopic myoma driller is introduced alongside the resectoscope under vision. It is a stainless steel wire with a terminal screw. This driller (figure 8) is used to tract the myoma at one side of the endometrial cavity to have an easy access to the base.

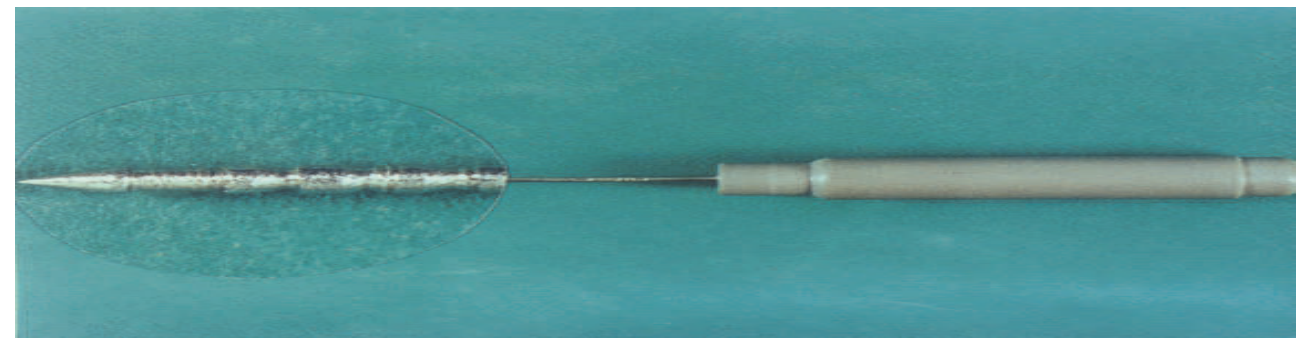

Fig. 8. Hysteroscopic myoma driller

This step is followed by extraction of the whole myoma through the primed cervical canal using a ring forceps. If some difficulty is encountered, the myoma is longitudinally bisected into 2 parts using resectoscopic knife electrode prior to extraction.

If an intramural extension is diagnosed, the following additional steps are done. A vertical linear incision is made over the whole length of the myoma to allow bulging of the myoma into the endometrial cavity i.e. to become a more submucous myoma like opening of the capsule at open myomectomy. IV injection of diluted $0.25 \mathrm{mg}$ ergometrine is given by the anesthiologist to promote uterine contraction in this non-pregnant uterus and to reduce the vascularity. Moreover, minimization of the intrauterine pressure is done to allow most of the myoma to become intracavitary "Myoma shift" as previously described. The base of the myoma is circumfrentially cut with resectoscope using the former mechanical technique.

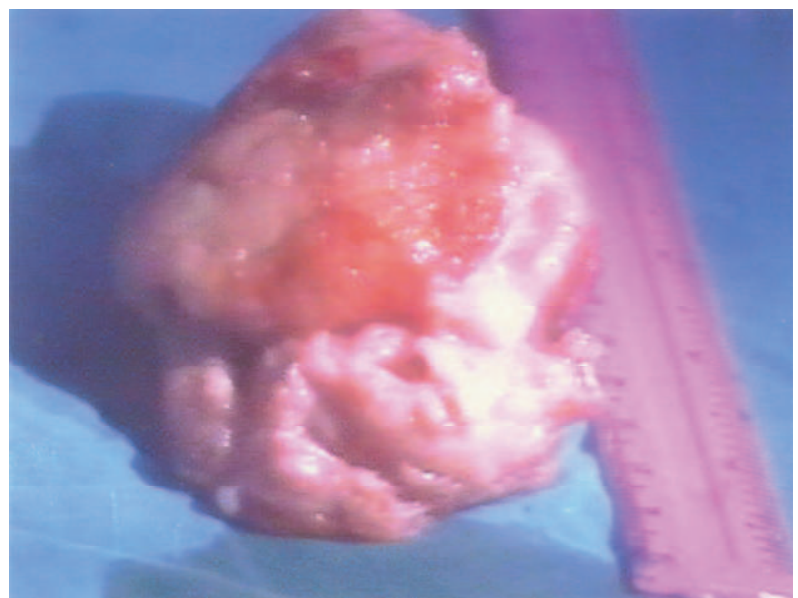

Fig. 9. Postmyomectomy tissue assessment. 
The resectoscope is reinserted after extraction of the myoma to ensure complete excision. Operative hysteroscopy is performed using continuous-flow resectoscope after cervical dilatation up to Hegar's 10 utilizing 1.5\% glycine as a distending medium. Operative notes should include comment on the feasibility of the operation, operating time calculated from the starting myomectomy until complete extraction of all tissues from the endometrial cavity, amount of fluid used for distending the uterine cavity, possible intraoperative or postoperative complications, and the amount of postoperative blood loss estimated by insertion of an intrauterine balloon at the end of the procedure. All the extracted tissues are evaluated (figure 9). Prophylactic antibiotics are prescribed for all cases.

\subsection{Postoperative care}

No need for hormonal treatment at all. Sometimes, an intrauterine balloon is left inside the endometrial cavity to control excessive bleeding from the bed of the myoma.

\subsection{Limitations of reconstructive HM}

It is the most dangerous hysteroscopic procedure due to possible excessive bleeding, prolonged time consumed for cutting the myoma into chips of tissues and their extraction outside the uterine cavity, the risks of fluid overload, possibility of incomplete resection, and liability to perforation. (71). Moreover, there are some studies concerned with the risk of uterine rupture in the subsequent pregnancy $(72,73)$. Most of complications of HM are encountered with large sized myomas, or those with intramural extension (grade 1 or 2 according to the European Society of Hysteroscopy classification). They represent definite nightmare for hysteroscopists even with sufficient experience to the extent that some studies preferred laparoscopic approach in such cases (74). Hysteroscopically, several studies tried to facilitate one-step complete excision. In a case report, succeeful removal of myoma up to $12 \mathrm{~cm}$ in one session is reported (75). A modified hysteroscopic approach for big myoma with or without intramural extension has been introduced by our team (70).This technique has been cited and quoted in subsequent publications (76) and comprehensive review articles (77) on this topic. It comprised combined resectoscopic and mechanical approaches to enucleate the myoma in a shorter time with minimal complication rate if compared to the standard morcellation technique. Moreover, it demonstrated some additive perioperative steps that facilitated the procedure like preoperative usage of misoprostol based on a RCT done by our team (66), intraoperative slow IV ergometrine administration, utilization of a novel hysteroscopic myoma driller, and performing a vertical incision on top of deeply impacted intramural myomata. If compared to a study on 44 cases published in the same year (78), the difference would be clear. They performed only circumferential incision at the level of myoma base followed by morcellation technique. They succeeded to perform this procedure in $41(93.1 \%)$ of 44 women. Of these, $38(92.6 \%)$ had myomas between 2 and $4 \mathrm{~cm}$ in diameter and $3(7.4 \%)$ had myomas exceeding $4 \mathrm{~cm}$. Mean operating time is 27 minutes (range 10-45 min). It seems very risky to perform morcellation of a big myoma with high possibility of fluid overload that would obligate the hysteroscopist to stop the procedure based on the recommendation of the anaesthesia team. As a trial to alleviate this risk, one case report is recently published utilizing our previously recommended basal circumferential incision followed by central vaporization, and intraoperative injection of prostaglandin F2alpha (76). Likewise, laser HM guided by laparoscopically assisted intraabdominal sonohysterography (LHMY-GLAIS) is described in a preliminary study (79). 
All these trials would be expected to open the door for more ideas on HM for myomata of considerable size. In this context, innovation of alternative hysteroscopically-guided devices would be promising. Moreover, studies on bipolar resectoscopic myomectomy utilizing saline $0.9 \%$ should be encouraged.

\subsection{Complications of HM (65)}

Complications of hysteroscopic myoma resection include hemorrhage, uterine perforation, damage to the cervix, and excessive absorption of the distention media (usually glycine) into the vascular system, which can cause metabolic disturbances. The most serious potential complication with hysteroscopic myomectomy is excessive absorption of distension media, which can cause pulmonary edema, hyponatremia, cerebral edema, and even death. This is especially true when using nonconducting distension solution with monopolar cautery. A surgeon should also be cautious with saline during resections with bipolar cautery since large volumes of fluid can lead to overload complications. A fluid management system that can accurately calculate the amount of absorbed fluid by measuring the inflow and outflow of distension fluid should be used. Intracervical injection of dilute vasopressin, in addition to reducing the force needed to dilate the cervix, has also been shown to decrease the absorption of distention fluid. In 1991, Corson and Brooks noted 1 case of heavy bleeding that required transfusion and 3 uterine perforations out of 92 patients undergoing hysteroscopic myoma resection. In 1993, Indman noted distension media complications in 2 of 51 women. Intrauterine synechiae can also occur after hysteroscopic myoma resection.

\subsection{Impact on the reproductive health}

Many studies have assessed fertility rates after hysteroscopic myomectomy and have noted pregnancy rates similar to those after abdominal myomectomy, approximately $60 \%$ Again, no studies include expectantly managed control groups (65).

\subsection{Poorly evidenced endoscopic myomectomy}

Laparoscopically-assisted transvaginal myomectomy has been described for posterior and fundal myomas where a posterior colpotomy is done to allow delivery of myomata and the uterus as well. Uterine reconstruction is then performed by conventional suturing performed transvaginally. The uterus is then replaced into its anatomical position and colpotomy is repaired. A final laparoscopic survey and lavage is performed $(80,81)$. Colposcopic myomectomy is first described by Baggish in 1990s. Thereafter, two case reports with cervical fibroids underwent laser $\mathrm{CO}_{2}$ excision under colposcopic guidance (82).

\subsection{Endoscopic myomectomy prior to IVF/ICSI}

The impact of uterine myoma on the outcome of IVF/ICSI is a very controversial topic. Many centers are overdoing myomectomy for nearly all myomata regardless size and site considerations. Contrary, other investigators have shown that fibroids don't exert a deleterious effect. Nevertheless, many studies have provided evidence that uterine myomas have a significant effect on IVF outcomes and there is a large body of evidence that treatment of uterine myomas increases fertility and pregnancy rates, and decreases the rate of pregnancy loss (83). There is no doubt that any cavity-distorting myoma should be removed whether completely submucous or interstitial myoma with submucous 
encroachment. This highlights the central role of prior hysteroscopy as well as saline infusion solonhysterography (SIS) as previously described (84). Controversy exists for interstitial and subserous myomata. The evidence supports treatment of all very large myomas $(>7 \mathrm{~cm})(83)$. Subserosal myomas that are smaller than $7 \mathrm{~cm}$ in size and intramural myomas of less than $4-5 \mathrm{~cm}$ in diameter appear to have little effect on IVF outcomes. Larger intramural and subserosal myomas present a clinical dilemma and more studies are needed to clarify a definitive plan for management (83). In a prospective controlled study, the distance between the intramural myomas and the endometrial lining did not appear to affect the IVF outcome. An insignificant tendency towards improvement of IVF outcome is found in myomas at more than $5 \mathrm{~mm}$ from endometrial lining (85).

\section{Keynote points}

Uterine myoma may affect fertility according to its size, site and associated pathology. Endoscopic approach has a definite role in its management. HM is the gold standard line of management of submucous myoma of suitable size. LM doesn't seem to be superior to conventional open myomectomy regarding fertility and is characterized by both short and long term drawbacks. Uterine myomata would affect IVF/ICSI outcome whenever disturbing the endometrial cavity or large sized. The impact of other types of myomata on IVF/ICSI deserves further studies.

\section{References}

[1] Atef M. Darwish. Fertility-enhancing Reconstructive Endoscopic Myomectomy in modern practice. Middle East Fertility Society Journal 2009; Vol. 14, No. 2, 25-29.

[2] Chew S, L C F. An assessment of present day laparoscopic surgery in Gynaecology. Singapore Journal of Obstetrics and Gynaecology 2001;32(1): 1-13.

[3] National Collaborating Centre for Women's and Children's Health. Fertility assessment and treatment for people with fertility problems. RCOG Press. London, 2004, Ch $7,8,9$.

[4] Wiedermann R, Hepp H. Selection of patients for IVF therapy or alternative therapy methods. Hum Rep 1989.;4:23-27.

[5] Watson A, Vandekerckhove P, Lilford R. Techiques for pelvic surgery in subfertility. Cochrane Database Syst Rev 2:CD00022, 2000.

[6] Ahmad G, Watson A, Vandekerckhove P, Lilford R. Techniques for pelvic surgery in subfertility.Cochrane Database Syst Rev. 2006 Apr 19;(2):CD000221.

[7] Sauer MV. Tubal infertility. The role of reconstructive surgery. In. Lobo RA, Mishell DR, Paulson RJ, Shoupe D. Infertility, Contraception and Reproductive Endocrinology. Boston, Blackwell Scientific Publications, 4th edition, 1997,Ch 36.

[8] Bateman BG, Nunley JW, Kitchen JD. Surgical management of distal tubal occlusion-are we making progress?. Fertil Steril 1987;48;523.

[9] Gomel V, Taylor PJ (Ed). Fertility-promoting procedures and assisted reproductive technology. In. Diagnostic and Operative Gynaecologic Laparoscopy. St Louis, Mosby-Year Book, Inc., 1995,Ch 15.

[10] Koh CH. Anastomosis of the fallopian tube. In. Tulandi T. Atlas of Laparoscopic and Hysteroscopic Techniques for gynaecologists. 2nd edition, London, W.B. Saunders, 1999. Ch 7. 
[11] Semm K, Mettler L. Technical progress in pelvic surgery via laparoscopy Am J Obstet Gynaecol 1980; 138:121-127.

[12] Hasson HM, Rotman C, Rana N, Sistos F, Dmowaki WP. Laparoscopic myomectomy. Obstet Gynaecol 1992; 80:884-888.

[13] Nezhat C, Nezhat F, Silfen SL, Schaffer N, Evans D. Laparoscopic myomectomy. Int J Fertil 1991; 36:275-280.

[14] Harris WJ. Uterine dehiscence following laparoscopic myomectomy. Obstet Gynecol 1992; 80:545-546.

[15] Dubuisson JB, Chavet X, Chapron C, Gregorakis SS, Morice P. Uterine rupture during pregnancy after laparoscopic myomectomy. Hum Reprod 1995; 10:1475-1477.

[16] Friedmann et al. Uterine rupture after laparoscopic Myomectomy. Acta Obstet Gynaecol Scand. 1996; 75: 683-4.

[17] Pelosi M, Pelosi MA. Spontaneous uterine rupture at thirty three weeks subsequent to previous superficial laparoscopic myomectomy. Am. J Obstet. Gynaecol. 1997; 177:1547-49.

[18] Dubuisson JB, Fauconnier A, Deffarges JV, Norgaard C, Kreiker G, Chapron C. Pregnancy outcome and deliveries following laparoscopic Myomectomy. Hum. Repro. 2000; 15: 869-73.

[19] Candiani GB, Fedele L, Parazzini, Villa L. Risks of recurrence after myomectomy. Br. J Obstet Gynaecol 1991; 98:385-389.

[20] Dubuisson JB, Lecuru F, Foulot H. Gonadotrophin-releasing hormone agonist and laparoscopic myomectomy. Clinical Therapeutics 1992; 14:51-55.

[21] Mais V, Ajossa S, Guerriero S, Mascia M, Solla E, Melis GB. Laparoscopic versus abdominal myomectomy: a prospective randomized trial to evaluate benefits in early outcome. Am J Obstet Gynaecol 1996; 174:654-658.

[22] Whittaker MD, Garry R. Patient satisfaction with laparoscopic-assisted removal of large myomas. J Am Assoc Gynaecol Laparosc 1996; 3(4,supplement):S55.

[23] Rossetti A, Sizzi O, Soranna L, Mancuso S, Lanzone A. Fertility outcome: long-term results after laparoscopic myomectomyGynaecol Endocrinol 2001;15(2):129-34.

[24] J Minim Invasive Gynecol. 2011 Jan-Feb;18(1):92-5. Epub 2010 Nov 20. Use of bidirectional barbed suture in laparoscopic myomectomy: evaluation of perioperative outcomes, safety, and efficacy. Einarsson JI, Chavan NR, Suzuki Y, Jonsdottir G, Vellinga TT, Greenberg JA.

[25] Dubuisson, J-B. and Chapron, C. (1996) Uterine fibroids: place and modalities of laparoscopic treatment. Eur. J. Obstet. Gynecol., 65, 91-94.

[26] Donnez, J., Mathieu, P.E., Bassil, S. et al. (1996) Laparoscopic myomectomy today. Fibroids: management and treatment: the state of the art. Hum. Reprod., 11, 18371840.

[27] Hasson, H.M., Rotman, C., Rana, N. et al. (1992) Laparoscopic myomectomy. Obstet. Gynecol., 80, 884-888.

[28] Cittadini, E. (1998) Laparoscopic myomectomy: the Italian experience. J. Am. Assoc. Gynecol. Laparoscop., 5, 7-9.

[29] Palomba S, Zupi E, Falbo, A, et al. A multicenter randomized, controlled study comparing laparoscopic versus minilaparotomic myomectomy: reproductive outcomes. Fertility and Sterility. Oct 2007;88:933-941. [Medline]. 
[30] Di Spiezio Sardo A, Mazzon I, Bramante S, et al. Hysteroscopic myomectomy: a comprehensive review of surgical techniques. Hum Reprod Update. Mar-Apr 2008;14:101-19.

[31] Minim Invasive Ther Allied Technol. 2011 Jan 19. Laparoscopic myomectomy in patients with uterine myomas associated with infertility. Hackethal A, Westermann A, Tchartchian G, Oehmke F, Tinneberg HR, Muenstedt K, Bojahr B

[32] Zullo F, Pellicano M, De Stefano R, et al. A prospective randomized study to evaluate leuprolide acetate treatment before laparoscopic myomectomy: efficacy and ultrasonographic predictors. Am J Obstet Gynecol. Jan 1998;178(1 Pt 1):108-12.

[33] Felberbaum RE, Küpker W, Krapp M, Gehl B, Ludwig M, Diedrich K.Preoperative reduction of uterine fibroids in only 16 days by administration of a gonadotrophinreleasing hormone antagonist (Cetrotide). Reprod Biomed Online. 2001;3(1):14-18

[34] Campo S, Garcea N. Laparoscopic myomectomy in premenopausal women with and without preoperative treatment using gonadoptropin-releasing hormone analogs. Human Reproduction. Jan 1999;14:44-48.

[35] Einarsson JI, Chavan NR, Suzuki Y, Jonsdottir G, Vellinga TT, Greenberg JA. Use of bidirectional barbed suture in laparoscopic myomectomy: evaluation of perioperative outcomes, safety, and efficacy. J Minim Invasive Gynecol. 2011 JanFeb;18(1):92-5.

[36] Zhao F, Jiao Y, Guo Z, Hou R, Wang M. Evaluation of loop ligation of larger myoma pseudocapsule combined with vasopressin on laparoscopic myomectomy. Fertil Steril. 2011 Feb;95(2):762-6.

[37] Chen SY, Huang SC, Sheu BC, Chang DY, Chou LY, Hsu WC, Chang WC. Simultaneous enucleation and in situ morcellation of myomas in laparoscopic myomectomy. Taiwan J Obstet Gynecol. 2010 Sep;49(3):279-84.

[38] Golan A, Sandbank O, Rubin A. Rupture of the pregnant uterus. Obstet Gynaecol 1980;56:549-54.

[39] Pelerme GR, Friedman EA. Rupture of the gravid uterus in the third trimester. Am J Obstet Gynaecol 1996;94:571.

[40] Acrangeli S, Pasquarette MM. Gravid uterine rupture after myolysis. Obstet Gynaeco. 1997;89:857

[41] Banas T, Klimek M, Fugiel A, Skotniczny KSpontaneous uterine rupture at 35 weeks' gestation, 3 years after laparoscopic myomectomy, without signs of fetal distress Journal of Obstetrics and Gynaecology Research 2005; 31 (6), 527-530.

[42] Tulandi T, Al-Took S. Endoscopic myomectomy. Laparoscopy and Hysteroscopy. Obstet Gynaecol Clin North Am 1999; 26(1):135-48

[43] Nezhat HC, Nezhat F, Rroemisch M, Seidman DS, Tazuke SI, Nezhat CR Pregnancy following laparoscopic myomectomy: preliminary results. Hum Reprod 1999;14(5):1219-21

[44] Nezhat C, Nezhat F, Bess O, Nezhat CH, Mashiach R. Laparoscopically assisted myomectomy: a report of a new technique in 57 cases. Int J Fertil 1994;39:39-44.

[45] Ostrazenski A: Extensive iatrogenic adenomyosis after laparoscopic myomectomy. Fertil Steril 1998;69(1):143-5.

[46] Garnet J D. Uterine rupture during pregnancy. Obstet Gynaecol 1964; 23:898-902.

[47] Nair S. Contemporary Management of Fibroids. Ann Acad Med Singapore 2003; 32:61523. 
[48] Dubuisson JB, Fauconnier A, Chapron C, Kreiker G,Norgaard C. Second look after laparoscopic myomectomy. Human Reprod 1998;13(8):2102-6.

[49] Bulletti C, Polli V, Glacomucci ,Flamigni C Adhesion formation after laparoscopic myomectomy J Am Gynaecol Laparosc 1996;3(4): 533-6.

[50] Griffiths A, D'Angelo A, Amso N. Surgical treatment of fibroids for subfertility.Cochrane Database Syst Rev. 2006 Jul 19;3:CD003857. Review.

[51] Pun TC, Chau MT, Lam C, Tang G, Leong L. Sonographic evaluation of myomectomy 'scars.' Acta Obstet Gynaecol Scand 1998;77:218.

[52] Keckstein J, Karageorgieva E, Darwish A, Grab D, Paulus W, Tuttlies F. Laparoscopic Myomectomy: Sonographic Follow-Up and Second-Look Laparoscopy for the Evaluation of a New Technique J Am Assoc Gynecol Laparosc. 1994;1(4, Part 2):S16.

[53] Darwish AM, Nasr AM, El-Nashar DA. Evaluation of postmyomectomy uterine scar. J Clin Ultrasound. 2005;26;33(4):181-186.

[54] Seracchioli R, Rossi S, Govoni F, et al. Fertility and obstetric outcome after laparoscopic myomectomy of large myomata: a randomized comparison with abdominal myomectomy. Hum Reprod. Dec 2000;15(12):2663-8.

[55] Alessandri F, Lijoi D, Mistrangelo E, et al. Randomized study of laparoscopic versus minilaparotomic myomectomy for uterine myomas. The Journal of Minimally Invasive Gynecology. Mar-Apr 2006;13:92-97.

[56] Buttram VC Jr, Reiter RC. Uterine leiomyomata: etiology, symptomatology, and management. Fertil Steril 1981;36:433-45.

[57] Verkauf BS. Myomectomy for fertility enhancement and preservation. Fertil Steril 1992;58:1-15.

[58] Pritts EA. Fibroids and infertility: a systematic review of the evidence. Obstet Gynecol Surv 2001;56:483-91.

[59] Varasteh NN, Neuwirth RS, Brucelevin, Keltz MD. Pregnancy Rates After Hysteroscopic Polypectomy and Myomectomy in Infertile Women. Obstetrics \& Gynecology 1999;94:168-171.

[60] McLucas B: Intrauterine applications of the resectoscope. Sur Gynecol Obstet 1991; 172(6):425-430.

[61] Sardo AD, Mazzon I, Bramante S, Bettocchi S, Bifulco G,Guida M, Nappi C HM: a comprehensive review of surgical techniques. Human Reproduction Update 2008; 14(2):101-119.

[62] Pasini A, Belloni C: Intraoperative complications of 697 consecutive operative hysteroscopies. Minerva Ginecol 2001;53(1):13-20.

[63] Hamou J: Electroresection of fibroids. In Endoscopic Surgery for Gynaecologists. Ed by Sutton C and Diamond M. London. Sauhders Co LTD, 1993, Ch41.

[64] Cohen LS, Valle RF. Role of vaginal sonography and hysterosonography in the endoscopic treatment of uterine myomas. Fertil Steril. Feb 2000;73:197-204

[65] Marquard KL, Chelmow D. Gynecologic Myomectomy. E Medicine. Aug 6, 2008

[66] Darwish AM, Ahmad AM, Mohammad AM. Cervical priming prior to operative hysteroscopy: a randomized comparison of laminaria versus misoprostol. Hum Reprod 2004; 19(10):2391-2394.

[67] Indman PD. Hysteroscopic treatment of submucous myomas. Clin Obstet Bynecol. Dec 2006;49:811-20. 
[68] Murakami T, Tachibana M, Hoshiai T, et al. Successful strategy for the hysteroscopic myomectomy of a submucous myoma arising from the uterine fundus. Fertil Steril. Nov 2006;86:1513.e19-22. [Medline].

[69] Loffer FD. Removal of large symptomatic intrauterine growths by the hysteroscopic resectoscope. Obstet Gynecol. Nov 1990;76:836-40

[70] Darwish A. Modified HM of large submucous fibroids. Gynecol Obstet Invest. 2003;56(4):192-6.

[71] Pasini A, Belloni C: Intraoperative complications of 697 consecutive operative hysteroscopies. Minerva Ginecol 2001;53(1):13-20.

[72] Hamou J: Electroresection of fibroids. In Endoscopic Surgery for Gynaecologists. Ed by Sutton C and Diamond M. London. Sauhders Co LTD, 1993, Ch41.

[73] Stamatellos I, Bontis J. The chance of success decreases whenever an intramural element is present hysteroscopic myomectomy European Clinics in Obstetrics and Gynaecology 2007;1,17-23.

[74] Wang CJ, Soong YK, Lee CL Laparoscopic myomectomy for large intramural and submucous fibroids. Int J Gynaecol Obstet. 2007;97(3):206-7.

[75] Kriplani A, Singh BM, Meena S. One-step hysteroscopic myomectomy: unusual cases and a review of the literature. J Laparoendosc Adv Surg Tech A. 2004;14(6):390-4.

[76] Murakami T, Tachibana M, Hoshiai T, Ozawa Y, Terada Y, Okamura K. Successful strategy for the HM of a submucous myoma arising from the uterine fundus. Fertil Steril. 2006; 86,5,1513.e19-22.

[77] Sardo AD, Mazzon I, Bramante S, Bettocchi S, Bifulco G,Guida M, Nappi C HM: a comprehensive review of surgical techniques. Human Reproduction Update 2008; 14(2):101-119.

[78] Litta P, Vasile C, Merlin F, Pozzan C, Sacco G, Gravila P, Stellia C. A new technique of HM with enucleation in Toto. The Journal of the American Association of Gynecologic Laparoscopists 2003;10,2;263-270.

[79] Kaseki H, Araki T, Valle R. Laser HM guided by laparoscopically assisted intraabdominal sonohysterography (LHMY-GLAIS): a preliminary report. Journal of Gynecologic Surgery 2001; 17(3): 79-86.

[80] Pelosi MA 3rd, Pelosi MA.Laparoscopic-assisted transvaginal myomectomy. J Am Assoc Gynecol Laparosc. 1997 Feb;4(2):241-6.

[81] Wang CJ, Yen CF, Lee CL, Soong YK. .Laparoscopic-assisted vaginal myomectomy. J Am Assoc Gynecol Laparosc. 2000 Nov;7(4):510-4.

[82] Penna C, Fallani MG, Fambrini M, Galassi D, Basile V, Marchionni M. Cervical myomectomy by laser CO2. Report of two cases. Minerva Ginecol. 2002;54(5):435-8.

[83] Bromer JG, Arici A. Impact of uterine myomas on IVF outcome. Expert Review of Obstetrics \& Gynecology 2008;3, 4,515-521.

[84] Darwish AM, Youssef AA. Screening sonohysterography in infertility. Gynecol Obstet Invest. 1999;48(1):43-7.

[85] Aboulghar, M.M., Al-Inany, H.G., Aboulghar, M.A., Serour, G.I., Mansour, R.T. Effect of myomectomy on the outcome of assisted reproductive technologies Middle East Fertility Society Journal 2004; 9 (3), 263-267. 


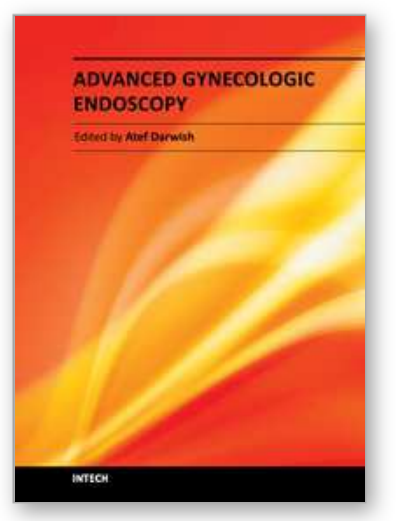

\author{
Advanced Gynecologic Endoscopy \\ Edited by Dr. Atef Darwish
}

ISBN 978-953-307-348-4

Hard cover, 332 pages

Publisher InTech

Published online 23, August, 2011

Published in print edition August, 2011

The main purpose of this book is to address some important issues related to gynecologic laparoscopy. Since the early breakthroughs by its pioneers, laparoscopic gynecologic surgery has gained popularity due to developments in illumination and instrumentation that led to the emergence of laparoscopy in the late 1980's as a credible diagnostic as well as therapeutic intervention. This book is unique in that it will review common, useful information about certain laparoscopic procedures, including technique and instruments, and then discuss common difficulties faced during each operation. We also discuss the uncommon and occasionally even anecdotal cases and the safest ways to deal with them. We are honored to have had a group of world experts in laparoscopic gynecologic surgery valuably contribute to our book.

\title{
How to reference
}

In order to correctly reference this scholarly work, feel free to copy and paste the following:

Atef M.M. Darwish (2011). Reconstructive Endoscopic Myomectomy, Advanced Gynecologic Endoscopy, Dr. Atef Darwish (Ed.), ISBN: 978-953-307-348-4, InTech, Available from:

http://www.intechopen.com/books/advanced-gynecologic-endoscopy/reconstructive-endoscopic-myomectomy

\section{INTECH}

open science | open minds

\section{InTech Europe}

University Campus STeP Ri Slavka Krautzeka 83/A 51000 Rijeka, Croatia

Phone: +385 (51) 770447

Fax: +385 (51) 686166 www.intechopen.com

\section{InTech China}

Unit 405, Office Block, Hotel Equatorial Shanghai No.65, Yan An Road (West), Shanghai, 200040, China 中国上海市延安西路65号上海国际贵都大饭店办公楼405单元 Phone: +86-21-62489820

Fax: $+86-21-62489821$ 
(C) 2011 The Author(s). Licensee IntechOpen. This chapter is distributed under the terms of the Creative Commons Attribution-NonCommercialShareAlike-3.0 License, which permits use, distribution and reproduction for non-commercial purposes, provided the original is properly cited and derivative works building on this content are distributed under the same license. 